\title{
Kv2 Channels Form Delayed-Rectifier Potassium Channels In Situ
}

\author{
Judith T. Blaine and Angeles B. Ribera \\ Department of Physiology and Biophysics, Medical Scientist Training Program, University of Colorado Health Sciences \\ Center, Denver, Colorado 80262
}

\begin{abstract}
A non inactivating potassium current known as the delayed rectifier plays a major role in membrane repolarization during an action potential. Whereas several candidate genes exist that code for potassium current, the identities of the molecular isotypes that are responsible in situ for membrane repolarization remain unidentified. We report that Kv2 channels play a major role in action potential repolarization. Kv2 channel elimination resulted in a reduction of the density of noninactivating potassium current and a prolonged impulse duration. In con-
\end{abstract}

Voltage-gated potassium channels determine key signaling properties in the adult nervous system (Adams et al., 1980; Rudy, 1988; Storm, 1990; Hille, 1992; Levitan and Rogawski, 1996). In addition, potassium currents undergo developmental modulation and dynamically regulate excitability as it emerges in the embryonic nervous system (Barish, 1986; O'Dowd et al., 1988; Spitzer and Ribera, 1998). In vivo, various types of voltage-gated potassium currents, such as noninactivating delayed-rectifier and inactivating " $\mathrm{A}$ " currents, are distinguishable on the basis of voltagedependent properties (Hodgkin and Huxley, 1952; Connor and Stevens, 1971; Adams et al., 1980; Hille, 1992). Numerous potassium channel genes have been identified that might serve as structural determinants of these different currents (Butler et al., 1989; Coetzee et al., 1999). However, progress in matching cloned vertebrate genes to in situ identified currents has met significant obstacles, including the large number of candidate potassium channel genes, lack of specific pharmacological tools, and difficulties in establishing a preparation that allows appropriate genetic manipulation, especially in the embryonic nervous system.

Kv2 (Shab) potassium channel genes code for molecular determinants of sustained potassium currents in several species ranging from flies to mammals (Butler et al., 1989; Frech et al., 1989; Pak et al., 1991; Hwang et al., 1992; Burger and Ribera, 1996; Patton et al., 1997; Coetzee et al., 1999) (but see Quattrocki et al., 1994). Although it is clear the Kv2 channels generate sustained potassium currents, so do other molecular species of potassium channels (e.g., Kv1, Kv3; Butler et al., 1989; Tsunoda and Salkoff, 1995; Rosenthal et al., 1996; Coetzee et al., 1999).

Here, we investigate the functional contributions of Kv2 chan-

Received Sept. 7, 2000; revised Nov. 21, 2000; accepted Dec. 21, 2000.

This work was supported by National Institutes of Health Grants MH11349 (J.T.B.), T32-NS07083, and NS25217 (A.B.R.). We thank M. Klymkowsky for the Ultra-GFP vector, I. Hsieh, S. Lockery, and N. C. Spitzer for assistance with mathematical modeling, A. Hofmann, M. Lazaroff, A. Linares, T. Nick, and K. Svoboda for discussion, and W. J. Betz for comments on this manuscript.

Correspondence should be addressed to Angeles B. Ribera, Department of Physiology and Biophysics, C-240, University of Colorado Health Sciences Center, Denver, CO 80262. E-mail: Angie.Ribera@UCHSC.edu.

Copyright $\odot 2001$ Society for Neuroscience 0270-6474/01/211473-08\$15.00/0 trast, suppression of noninactivating current carried by Kv1 channels was much less effective in increasing action potential durations. Thus, whereas different potassium channels encode sustained potassium current, their contributions to action potential repolarization vary and require direct examination in situ. Our results indicate that Kv2 subunits function as classic delayed-rectifier channels in vertebrate neurons.

Key words: Kv2 channels; potassium current; delayed rectifier; spinal neurons; Xenopus embryo; action potential nels to voltage-dependent potassium current $\left(I_{\mathrm{Kv}}\right)$ and membrane repolarization of embryonic spinal neurons. We focus on $I_{\mathrm{Kv}}$ because of the pivotal role it plays in maturation of excitability (Barish, 1986; O’Dowd et al., 1988; Spitzer and Ribera, 1998). In Xenopus, Kv2.2 transcripts are present in the spinal cord during the period when action potentials mature from long-duration calcium-dependent impulses to brief sodium-driven spikes (Gurantz et al., 1996; Ribera and Burger, 1996). Kv2.2 channels are thus candidate structural determinants of $I_{\mathrm{Kv}}$. However, levels of channel transcripts do not always reflect the amount of protein or current produced (Xu et al., 1996). Thus, the contribution of each individual $\mathrm{Kv}$ channel isotype to current generation requires direct functional analysis in situ.

We reduced Kv2 channel function by overexpressing a dominant-negative $\mathrm{Kv} 2$ subunit in embryonic neurons at early stages of differentiation; this dominant-negative subunit coassembles with either Kv2.1 or Kv2.2 subunits to produce nonfunctional channels (Blaine and Ribera, 1998). In a subpopulation of neurons, $I_{\mathrm{Kv}}$ was partially suppressed. Furthermore, action potential durations were dramatically prolonged. In contrast, functional elimination of another Kv subfamily that also codes for sustained potassium current $(\mathrm{Kv} 1)$ had only subtle effects on action potential duration despite pronounced effects on $I_{\mathrm{Kv}}$ density (Ribera, 1996). Finally, mathematical modeling accounted well for the effects of elimination of Kv1 but not Kv2 channel function.

\section{MATERIALS AND METHODS}

RNA synthesis. Plasmids were linearized and capped, and sense RNAs were generated in vitro. RNA concentrations and integrity were determined spectrophotometrically and by gel electrophoresis.

Embryos and microinjection protocols. In vitro fertilization and embryo injections were performed as described previously (Jones and Ribera, 1994; Ribera, 1996) with the following modifications. Each blastomere of a two-cell stage Xenopus embryo was injected, with either green fluorescent protein (GFP) and mutant Kv2.2 RNAs or RNase-free rhodamineconjugated dextran; Kv1.1 RNA was coinjected with dextran as described previously (Ribera, 1996). GFP and mutant Kv1.1 RNAs were injected at a concentration of $60-80 \mathrm{pg} / \mathrm{nl}$, whereas dominant-negative Kv2.2 RNA was used at $100-150 \mathrm{pg} / \mathrm{nl}$. The dominant-negative Kv2.2 subunit is expected to coassemble with either Kv2.1 or Kv2.2 subunits. However, Kv2.1 mRNA has not been detected in Xenopus spinal neurons using 
either in situ hybridization or single-cell RT-PCR (Burger and Ribera, 1996; Gurantz et al., 1996).

Spinal neuron cultures. Stage 18-19 embryos (Nieuwkoop and Faber, 1967) were viewed under epifluorescence to identify embryos expressing GFP and rhodamine fluorescence on opposite sides of the neural tube. Isolated cell cultures were prepared as described previously (Spitzer and Lamborghini, 1976; Blair, 1983; Ribera and Spitzer, 1989). A 10-15 min incubation in divalent cation solution, without enzymatic treatment, sufficed for cell dissociation (Spitzer and Lamborghini, 1976). Neurons were studied within $27 \mathrm{hr}$ of plating. The acute nonenzymatic dissociation of neurons and brief time in culture combines advantages of both in vivo (e.g., normal development) and in vitro (e.g., spatially compact, isolated cells) model systems. Neurons in culture were identified as either control (rhodamine-positive) or + Mutant (GFP-positive).

Electrophysiological methods. Tight-seal, whole-cell recordings (Hamill et al., 1981) were made from immature (3-7 hr in culture) or mature (15-27 hr in culture) neurons. Whole-cell currents were recorded with an Axopatch 1-D amplifier (Axon Instruments, Foster City, CA) in conjunction with a TL-1 data interface and pClamp6. Recordings were obtained at room temperature only from neurons with short processes $(<50 \mu \mathrm{m})$. Electrodes were pulled from borosilicate glass and had resistances ranging from 2 to $3.9 \mathrm{M} \Omega$ when filled with the standard pipette solution (in mM: $100 \mathrm{KCl}, 10$ EGTA, and 10 HEPES, pH 7.4).

Cell capacitance was used to determine membrane surface area $(1$ $\mu \mathrm{F} / \mathrm{cm}^{2}$ ) and normalization of current amplitudes to densities. Recordings were excluded if the access resistance changed during a recording or if the input resistance was $<0.5 \mathrm{G} \Omega$. The neuronal membrane was held at $-80 \mathrm{mV}$ and stepped for $60 \mathrm{msec}$ in $10 \mathrm{mV}$ increments to voltages ranging between -60 and $+90 \mathrm{mV}$. Currents were filtered at $5 \mathrm{kHz}$ and digitized at $25 \mathrm{kHz}$. Leak subtraction was achieved using a modified $\mathrm{P} / 4$ protocol (pClamp6).

For $I_{\mathrm{Kv}}$, the bath solution contained $80 \mathrm{~mm} \mathrm{NaCl}, 3 \mathrm{mM} \mathrm{KCl}, 5 \mathrm{~mm}$

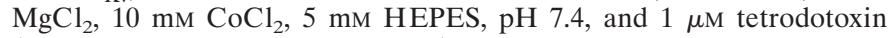
(TTX; Calbiochem, La Jolla, CA). Steady-state $I_{\mathrm{Kv}}$ amplitudes were measured by averaging values during a $7 \mathrm{msec}$ interval at the end of the pulse. $I_{\mathrm{Ca}}$ was recorded using a bath solution containing $40 \mathrm{mM} \mathrm{NaCl}, 40$ mM TEA, $3 \mathrm{~mm} \mathrm{KCl}, 10 \mathrm{~mm} \mathrm{CaCl} 2,5 \mathrm{~mm}$ HEPES, pH 7.4, and $1 \mu \mathrm{M}$ TTX. Electrodes were filled with $100 \mathrm{~mm} \mathrm{CsCl}, 10 \mathrm{~mm}$ tetraethylammonium$\mathrm{Cl}, 10 \mathrm{~mm}$ EGTA, and $10 \mathrm{~mm}$ HEPES, pH 7.4, with CsOH.

Conductance densities were obtained by dividing current densities by driving force using a calculated potassium equilibrium potential of -91.6 $\mathrm{mV}$. Conductance-voltage $(G-V)$ data were fit with the Boltzmann equation $\left(G=G_{\max } /\left\{1+\exp \left[\left(V_{1 / 2}-\mathrm{V}\right) / k\right]\right\}\right)$ to obtain the maximal $G_{\max }, V_{1 / 2}$, and slope factor $(k)$. Similar values were obtained when $G-V$ curves were constructed by measuring the amplitude of tail currents when the membrane was returned to -40 rather than $-80 \mathrm{mV}$, suggesting that single-channel current-voltage relationships were linear over the voltage range examined. Furthermore, there was no correlation between current amplitude-density and the reversal potential of the current, suggesting that $E_{\mathrm{k}}$ was constant during the $60 \mathrm{msec}$ depolarization. Current and conductance-density plots were not corrected for the voltage error introduced by the series resistance, which ranged between 3 and $9 \mathrm{M} \Omega$. Time to half-maximum current $\left(t_{1 / 2}\right)$ was measured using Axograph 3. For examination of $t_{1 / 2}$ and $G_{\max }$ values for $I_{\mathrm{Kv}}$ of individual neurons, we binned values and then plotted the percentage of neurons having the value in a particular bin (histograms of Figs. 3, 4).

Action potentials were recorded in the current-clamp mode. The neuronal membrane potential was set to $-80 \mathrm{mV}$ by steady-state current injection, and depolarizing current $(2.5 \mathrm{msec})$ was injected to elicit an impulse. The bath solution contained (in $\mathrm{mm}$ ): $125 \mathrm{NaCl}, 3 \mathrm{KCl}, 10$ $\mathrm{CaCl}_{2}$, and 5 HEPES, $\mathrm{pH}$ 7.4. Analysis of action potentials entailed measurement of the following parameters: overshoot, amplitude, maximum rate of rise, time to peak, and time to half-decay from the peak. We refer to the time to half-decay as the duration of the action potential, because we are interested primarily in repolarization of the action potential.

Data analysis. Mean values \pm SEM are presented. Differences between means were analyzed using the nonparametric Mann-Whitney $U$ test (two-tailed), and $p$ values $\leq 0.05$ indicated statistical significance.

\section{RESULTS}

If $\mathrm{Kv} 2$ channels contribute to the endogenous $I_{\mathrm{Kv}}$, neurons containing exogenous mutant $\mathrm{Kv} 2$ transcripts (+Mutant) would be expected to display alterations in $I_{\mathrm{Kv}}$ such as a reduction in

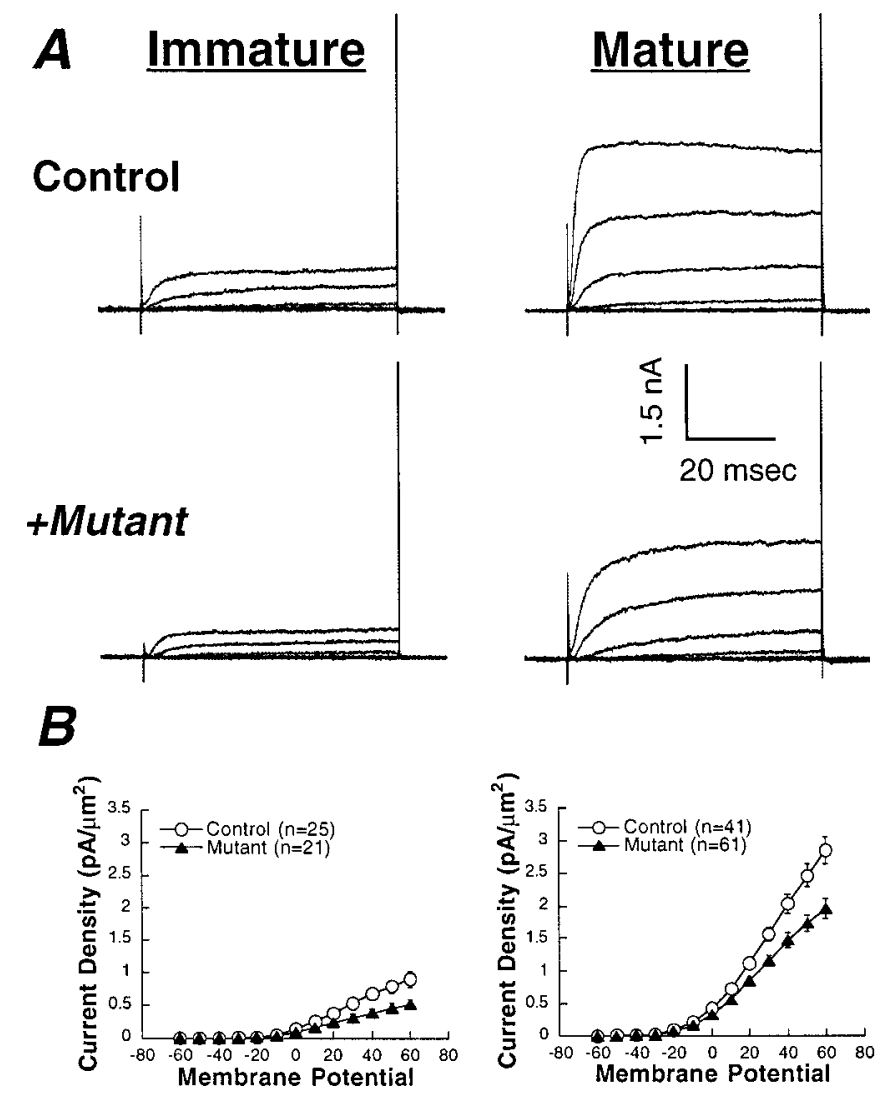

Figure 1. Elimination of Kv2 channel function led to a reduction in $I_{\mathrm{Kv}}$ density. $A, I_{\mathrm{Kv}}$ was recorded from control (top) or + Mutant (bottom) neurons at either immature (left) or mature (right) stages. The neuronal membrane was held at $-80 \mathrm{mV}$ and stepped to potentials ranging between -60 and $+90 \mathrm{mV}$. Currents elicited for steps to $-60,-40,-20,0$, +20 , and $+40 \mathrm{mV}$ are shown. $B$, Current density-voltage $(I-V)$ plots for $I_{\mathrm{Kv}}$ recorded from immature (left) or mature (right) neurons. At both stages, the dominant-negative Kv2 mutant led to a reduction in current density over a range of voltages.

density. Indeed, mean $I_{\mathrm{Kv}}$ densities in + Mutant neurons were 40 and $26 \%$ smaller than those in corresponding controls at immature and mature times in culture ( $p<0.04 ;+30 \mathrm{mV}$; Fig. 1). These data indicate that Kv2 channels contribute to the endogenous $I_{\mathrm{Kv}}$ at both early and mature times. In control neurons, $I_{\mathrm{Kv}}$ showed its normal developmental threefold increase in density (Fig. 1). Similarly, in + Mutant neurons, $I_{\mathrm{Kv}}$ displayed an approximately threefold increase in density during the same developmental period, suggesting that upregulation of other Kv channels persists.

The reduction in $I_{\mathrm{Kv}}$ density is consistent with the known expression pattern of Kv2.2 mRNA and the documented effects of the dominant-negative subunit on Kv2 channel function (Burger and Ribera 1996; Gurantz et al., 1996; Blaine and Ribera, 1998). Nonetheless, we examined the possibility that the mutant subunit might have additional or nonspecific actions that would lead indirectly to a reduction in $I_{\mathrm{Kv}}$. Measures of passive membrane properties were similar in Control and +Mutant neurons (Table 1 ), suggesting a lack of nonspecific effects. Furthermore, heterologous coexpression of dominant-negative Kv2.2 with Kv1.1 subunits did not reduce current amplitudes compared with those induced by the same dose of Kv1.1 RNA injected alone $(n=32$; data not shown). In addition, we examined another voltagedependent current, calcium current $\left(I_{\mathrm{Ca}}\right) . I_{\mathrm{Ca}}$ did not differ be- 
Table 1. Comparison of membrane properties of Control and +Mutant neurons

\begin{tabular}{llrlrl} 
& \multicolumn{1}{l}{ Control } & & & + Mutant & \\
\cline { 2 - 3 } \cline { 5 - 6 } Property & \multicolumn{1}{c}{ Immature } & \multicolumn{1}{c}{ Mature } & & Immature & \multicolumn{1}{c}{ Mature } \\
\hline Input resistance $(\mathrm{G} \Omega)$ & $0.9 \pm 0.1(25)$ & $0.7 \pm 0.1(21)$ & & $0.8 \pm 0.1(41)$ & $0.7 \pm 0.1(61)$ \\
Cell capacitance $(\mathrm{pF})$ & $20.0 \pm 0.5(25)$ & $22.5 \pm 0.8(21)$ & & $21.0 \pm 0.6(65)$ & $21.2 \pm 0.5(93)$ \\
\hline
\end{tabular}

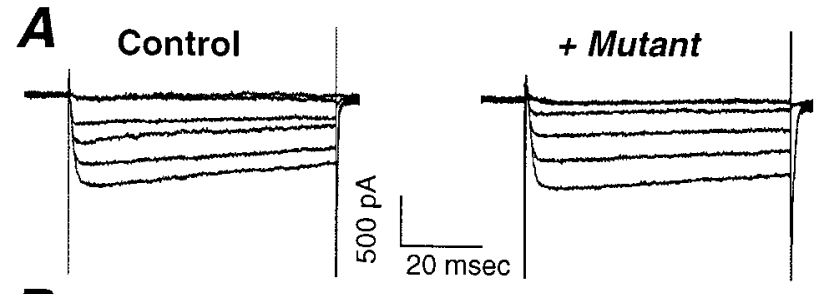

$B$

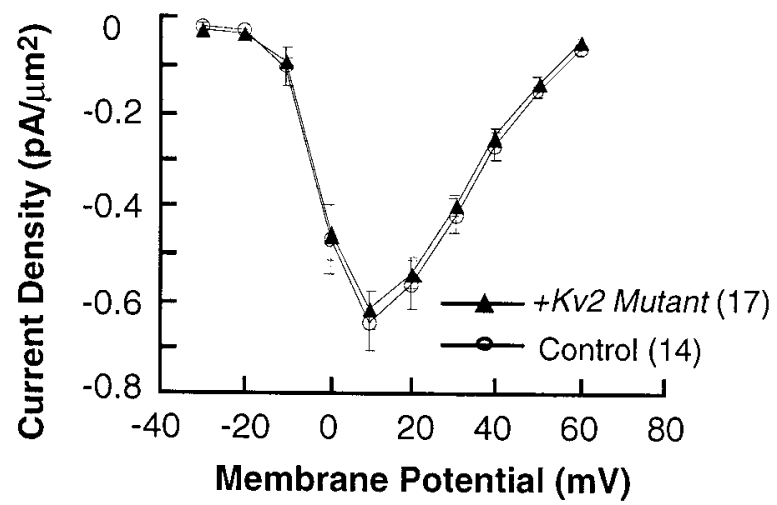

Figure 2. Elimination of Kv2 channel function did not affect calcium current $\left(I_{\mathrm{Ca}}\right)$. A, Representative $I_{\mathrm{Ca}}$ traces recorded from mature control (left) and + Mutant (right) neurons are similar. The neuronal membrane was held at $-80 \mathrm{mV}$, and currents were elicited by stepping the membrane to potentials ranging between -60 and $+90 \mathrm{mV}$. Currents elicited by steps to $-30,-20,+20,+30,+40$, and $+50 \mathrm{mV}$ are shown. $B$, Peak density and voltage dependence were similar for control and +Mutant neurons.

tween Control and + Mutant neurons, further demonstrating the specificity of the mutant Kv2 subunit (Fig. 2).

In contrast to effects on current density, overexpression of the dominant-negative Kv2 subunit did not affect the kinetics of activation of $I_{\mathrm{Kv}}$. There was no significant difference in mean $t_{1 / 2}$ values for $I_{\mathrm{Kv}}$ recorded from immature or mature +Mutant neurons compared with age-matched controls (Fig. 3A,B). Spinal neurons represent a heterogeneous population of neurons, and it is possible that the mean results could obscure effects in subpopulations of neurons. However, examination of histograms of $t_{1 / 2}$ values for $I_{\mathrm{Kv}}$ recorded from individual neurons revealed similar distributions (Fig. 3C,D).

Examination of the effects of the mutant Kv2 subunit on current density were evident over a broad range of voltages (Fig. $1 B$ ), suggesting a decrease in the number of functional channels. To examine this possibility more directly, we constructed conductance density versus voltage $(G-V)$ plots. Control neurons showed the normal developmental increase in conductance density (Fig. $4 A, B$ ). Similarly, conductance density was developmentally upregulated in + Mutant neurons. However, both immature and mature + Mutant neurons demonstrated a decrease in con- ductance density compared with stage-matched controls. Maximal conductance density $\left(G_{\max }\right)$ values for immature + Mutant and Control neurons were $3.9 \pm 0.5$ and $6.5 \pm 0.9 \mathrm{pS} / \mu^{2}$, respectively $(p<0.05)$, indicating that overexpression of the mutant subunit produced a $40 \%$ reduction in $G_{\max }$. In mature + Mutant and Control neurons, $G_{\max }$ values were $13.7 \pm 1.0$ and $21.5 \pm 1.5 \mathrm{pS} / \mu \mathrm{m}^{2}(p<0.0002)$, indicating that overexpression of the mutant subunit reduced $G_{\max }$ to the same extent in immature and mature neurons. Because the reduction in $G_{\max }$ obtained at immature and mature times did not vary (40 and 36\%, respectively), the inferred proportions of Kv2 channels are similar. The mutant subunit may have produced this effect by decreasing either the number of functional channels, the single-channel conductance, or $\mathrm{P}_{\text {open }}$. These results suggest that functional Kv2 channels are not selectively upregulated during development.

At early times, reductions in current densities ( $+30 \mathrm{mV}$; Fig. 2) and $G_{\max }$ were similar (40 vs $36 \%$ ). However, these values differed at late times ( 26 vs $36 \%$ ). This difference might arise if the voltage dependence of steady-state activation is altered by elimination of Kv2 channels in mature but not immature neurons. In immature Control or + Mutant neurons, $V_{1 / 2}$ was the same (18.9 \pm 1.9, Control; $18.9 \pm 1.8,+$ Mutant $)$. In contrast, there was a significant, albeit small $(\sim 4 \mathrm{mV})$, leftward shift in the average $V_{1 / 2}$ of currents recorded from mature +Mutant neurons compared with controls (Fig. $4 B$, inset). The shift in $V_{1 / 2}$ may arise from the series resistance and a larger voltage error when current amplitudes are increased, as in mature neurons. However, in a subset of neurons $(n=18)$, series resistance was electronically compensated, and a significant leftward shift in $V_{1 / 2}$ was still observed (Fig. 4E,F).

Examination of conductance densities in individual neurons revealed that the mutant subunit did not result in complete elimination of $I_{\mathrm{Kv}}$ in any neuron (Fig. $4 B, D$ ). Similar results were obtained when the dose of mutant RNA used was either 100 or $150 \mathrm{pg} / \mathrm{nl}$, suggesting that the concentrations of RNA used were saturating. Furthermore, this dose was higher than that used previously for overexpression of dominant-negative Kv1 subunits (80 pg/nl; Ribera, 1996). These data are consistent with the possibilities that non-Kv2 channels carry the residual $I_{\mathrm{Kv}}$ remaining after elimination of $\mathrm{Kv} 2$ channels and that multiple molecular species of potassium channels contribute to the total $I_{\mathrm{Kv}}$.

The mutant Kv2 subunit dramatically decreased current density without inducing obvious effects on activation kinetics. In contrast, antisense suppression of Kv3.1 subunits in Xenopus spinal neurons led simultaneously to a slowing of the activation kinetics and a reduction in current density (Vincent et al., 2000). To enhance detection of subtle effects of the Kv2 mutant on activation kinetics, we examined simultaneously activation kinetics and conductance density in individual neurons (Fig. 5). Whereas $G_{\max }$ was clearly reduced in a large proportion of + Mutant neurons, $t_{1 / 2}$ values in these neurons were not different from controls. In sum, the results indicate that elimination of Kv2 channels 


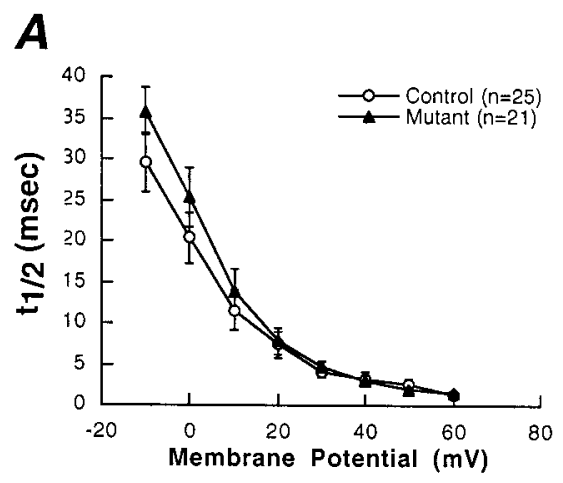

Figure 3. Elimination of Kv2 channel function had minimal effect on activation kinetics of $I_{\mathrm{Kv}}$. $A, B$, Time to half maximum $\left(t_{1 / 2}\right)$ of $I_{\mathrm{Kv}}$ recorded from either immature $(A)$ or mature $(B)$ neurons. At either stage in culture, overexpression of the dominant-negative subunit led to minimal if any difference in the average $t_{1 / 2}$. $C, D$, Distribution of $t_{1 / 2}$ values in individual neurons also revealed little difference between control and + Mutant neurons at either immature $(C)$ or mature $(D)$ stages. The histograms present data obtained $+0 \mathrm{mV}$, a voltage at which the average values showed a small, nonsignificant difference $(A, B)$.

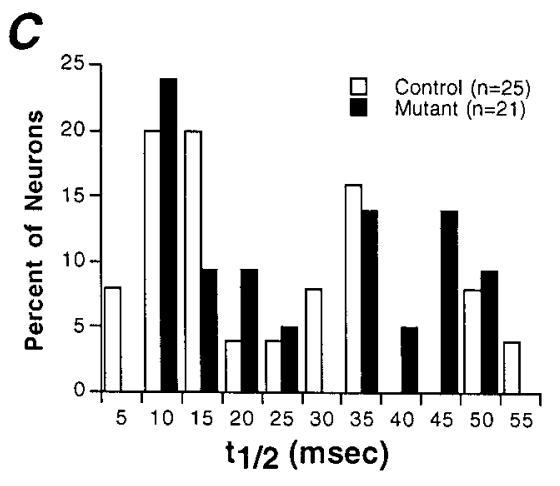

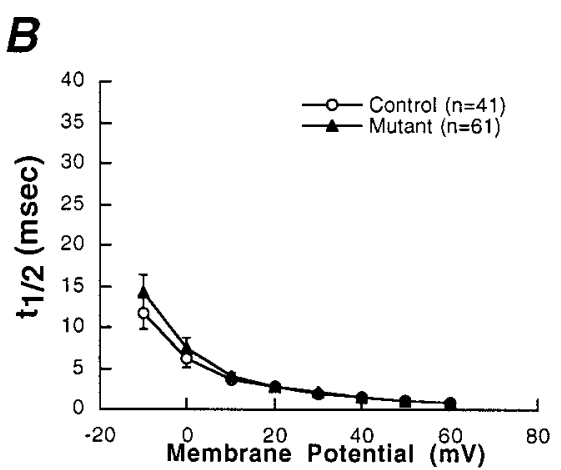

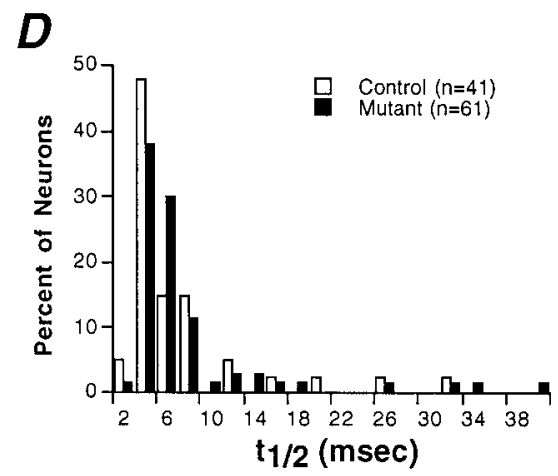

ledto a reduction in $G_{\max }$, a small negative shift in $V_{1 / 2}$ but no change in $t_{1 / 2}$.

Given the pivotal role $I_{\mathrm{Kv}}$ plays in maturation of the action potential, alterations in its properties would be expected to alter the waveform of the action potential (Barish, 1986; O'Dowd et al., 1988; Lockery and Spitzer, 1992). We incorporated the observed changes in $G_{\max }$ and $V_{1 / 2}$ of $I_{\mathrm{Kv}}$ into a mathematical model of the action potential to calculate effects on the impulse (Lockery and Spitzer, 1992). We also simulated action potentials produced by reducing $G_{\max }$ alone, a condition modeling suppression of Kv1 channels which was previously found to reduce current density (Ribera, 1996). Reduction of current density by itself (i.e., suppression of Kv1 channels) resulted in a slightly more prolonged action potential than did reduction of current density combined with a negative shift in $V_{1 / 2}$ (simulation of Kv2 channel elimination). The durations of the simulated impulses were prolonged by factors of 1.25 and 1.11, respectively.

We compared simulated action potentials to ones recorded from mature control and $+K v 1$ or $+K v 2$ Mutant neurons. Suppression of Kv1 channel function led to an average 1.5-fold (but statistically not significant) prolongation of the impulse duration, which closely matched the mathematical prediction $(1.25$-fold increase; see Fig. 7A, Table 2). Elimination of Kv2 channel function resulted in an average fourfold increase in action potential duration in +Mutant neurons compared with controls (see Fig. 7A, Table 2). This finding contrasts dramatically with the simulated impulse, which was prolonged by a factor of only 1.11 (Fig. 6). In individual neurons, dominant-negative Kv1 subunits increased the duration by at most a factor of 4 , whereas mutant Kv2 subunits produced up to a 35-fold increase (Fig. 7B, inset). Surprisingly, Kv2 currents played a major role in sculpting the waveform of the impulse, a result not predicted by the mathematical model.

Nonspecific effects are unlikely to account for the increased duration of the impulse because passive membrane properties and $I_{\mathrm{Ca}}$ were unaffected (Fig. 2, Table 1). Furthermore, there was no significant difference in the overshoot of action potentials recorded from + Mutant or control neurons (Table 2). The maximum rates of rise did not differ significantly between control and $+K v 2$ Mutant neurons or between $+K v 1$ and $+K v 2$ Mutant neurons; however, there was a difference between control and $+K v 1$ Mutant neurons (Table 2). Overall, these latter findings suggest that sodium current densities were unaffected by the Kv2 dominant-negative subunit, although there may have been effects of the Kv1 dominant-negative subunit. Resting membrane potentials recorded from $+K v 1$ or $+K v 2$ Mutant neurons appeared more depolarized than those recorded from controls (Table 2), but the differences were not statistically significant. Furthermore, there was no correlation between resting membrane potential and impulse duration (data not shown). Moreover, for recording of action potentials, the holding potential of the neuronal membrane was forced to $-80 \mathrm{mV}$ by injection of steady current.

The mathematical model accounted well for the observed effects of elimination of Kv1 but not Kv2 channels (compare Figs. $6,7)$. An $82 \%$ reduction in $G_{\max }$ was required to simulate the average fourfold increase of the impulse duration observed after elimination of Kv2 channel function (Fig. 6). Such a dramatic reduction in channel number is much larger than that produced by Kv2 channel elimination (Fig. $4 A, B$ ). Taken together, the results indicate that ventral spinal neurons provide an appropriate environment for $\mathrm{Kv} 2$ channels to function in situ as efficient delayed-rectifier channels.

\section{DISCUSSION}

Our results demonstrate that efficient membrane repolarization during an action potential requires Kv2 channel function in some Xenopus spinal neurons. These data are consistent with the restricted expression pattern of Kv2.2 gene in the Xenopus spinal 

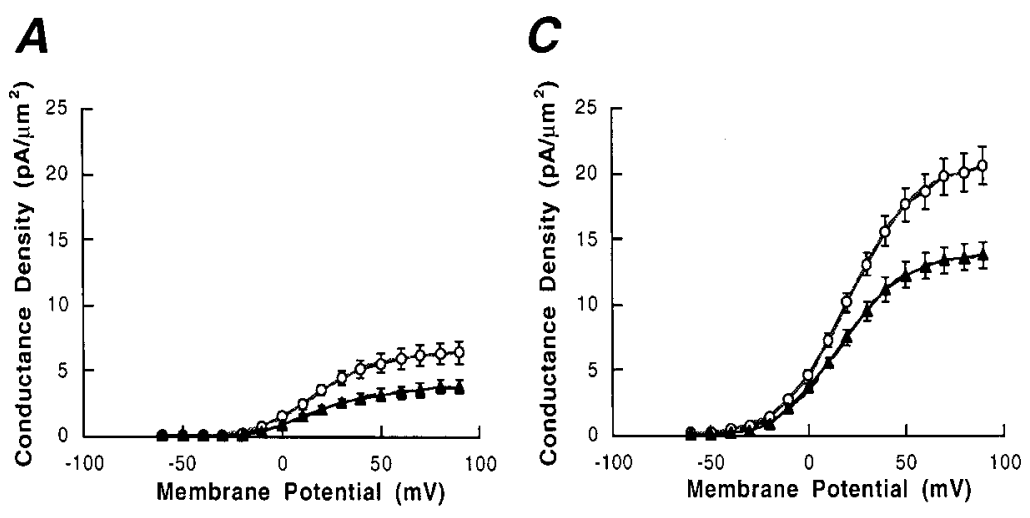

E
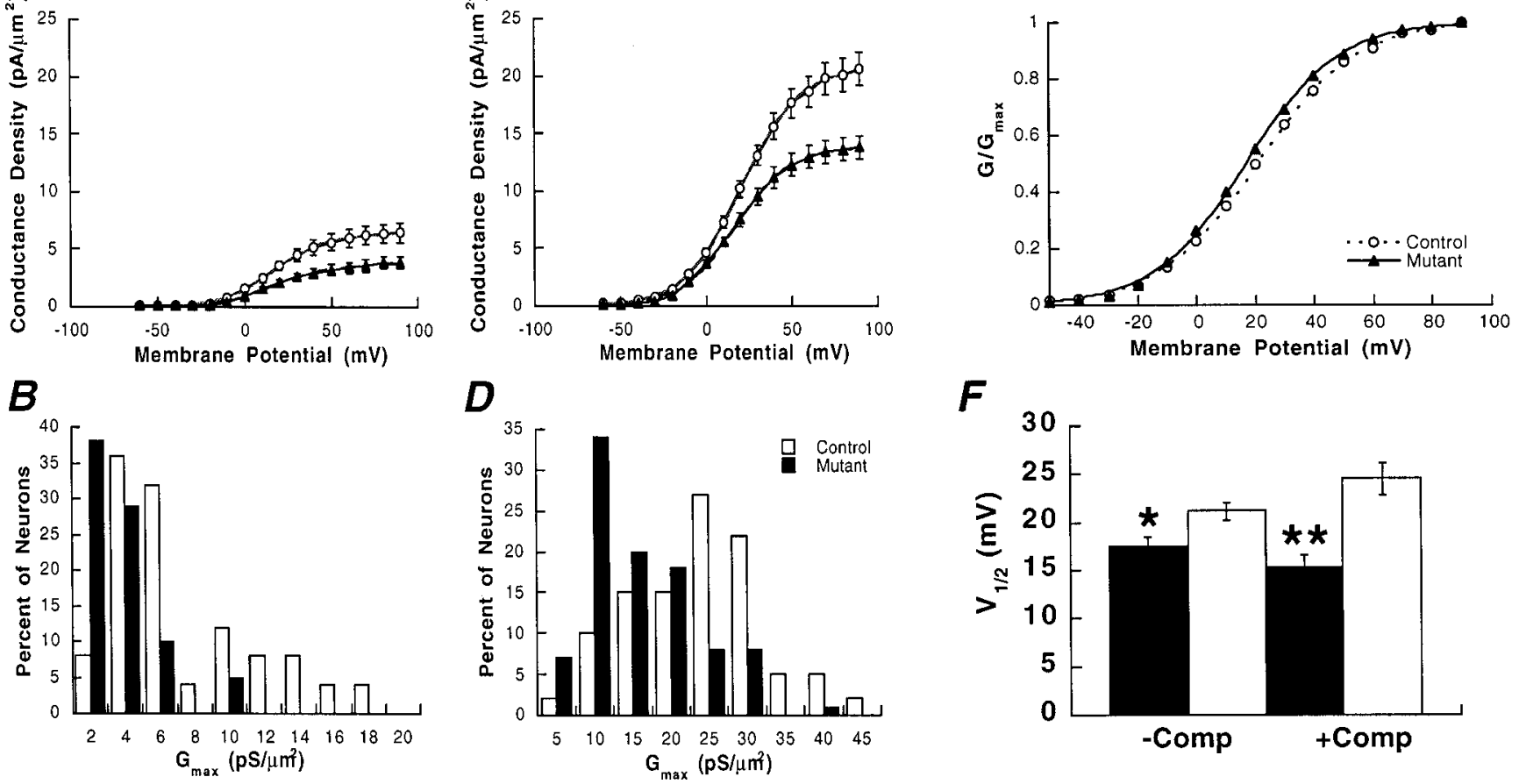

Figure 4. Elimination of $\mathrm{Kv} 2$ channel function reduced the maximum conductance density $\left(G_{\max }\right) . A$, $C$, Conductance density-voltage plots for $I_{\mathrm{Kv}}$ recorded from either control or + Mutant neurons at immature $(A)$ and mature $(C)$ stages. Overexpression of the Kv2 mutant subunit led to a $\sim 40 \%$ reduction in the average conductance density at both stages. $B, D$, Histograms for $G_{\mathrm{max}}$ of $I_{\mathrm{Kv}}$ recorded from individual immature $(B)$ and mature $(D)$ neurons. The distribution was shifted to smaller values of $G_{\max }$ for + Mutant neurons at both immature $(B)$ and mature $(D)$ stages. $E$, At mature stages, overexpression of the dominant-negative subunit shifted $V_{1 / 2}$ by approximately $-4 \mathrm{mV}$, as determined by fits to the Boltzmann equation (see Materials and Methods); in this panel, the lines through the data are the Boltzmann fit. $F$, Results for data that were either not corrected ( - Comp) or corrected (+Comp) electronically for the series resistance are shown; ${ }^{*} p<0.005,{ }^{* *} p<0.002$ (control vs + Mutant).

cord (Burger and Ribera, 1996). In addition, $I_{\mathrm{Kv}}$ was not completely eliminated in any neuron, and some neurons appeared resistant to the mutant Kv2 subunit (Figs. 1, 4). One possible scenario is that Kv2 channels are found in a subset of spinal neurons in combination with other Kv channels. A similar conclusion has been reached for mammalian CNS neurons by comparison of the properties of whole-cell potassium current to the $\mathrm{Kv}$ gene expression profile of individual cells (Martina et al., 1998; Baranauskas et al., 1999). In contrast, Kv2 (Shab) channels are the sole determinant of sustained potassium current in Dro-
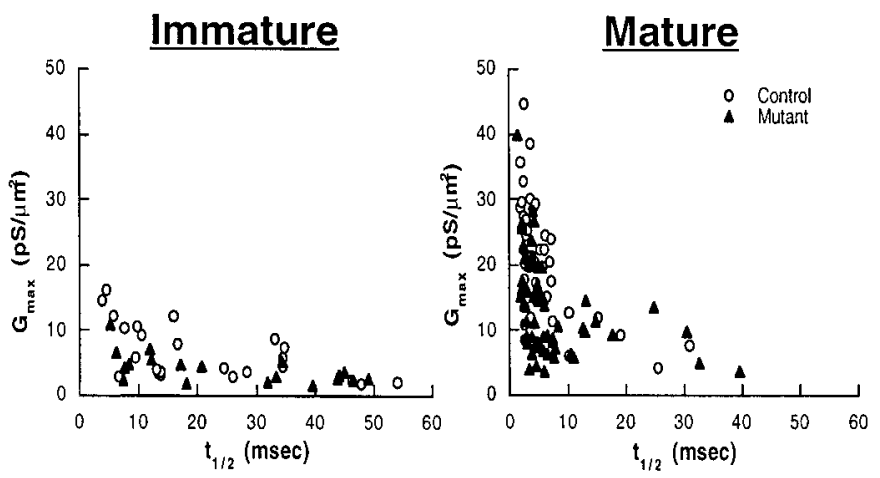

Figure 5. Elimination of Kv2 channels led to reduction in $G_{\max }$ without effects on activation kinetics. Plots for $G_{\max }$ as a function of $t_{1 / 2}$ for $I_{\mathrm{Kv}}$ recorded from individual immature and mature neurons reveal that the principal effect of the Kv2 mutant subunit was on conductance rather than activation kinetics. sophila neurons (Tsunoda and Salkoff, 1995). Interpretation of our data warrants caution because the exact dose of dominantnegative Kv2 RNA delivered to any individual neuron was unknown. However, we obtained similar results with two different concentrations of dominant-negative Kv2 RNA, suggesting that saturating dosages were used.

Overexpression of the dominant-negative Kv2 subunit resulted in slower activation kinetics of $I_{\mathrm{Kv}}$. These data were surprising in light of the slow activation of heterologously expressed Kv2 channels (Burger and Ribera, 1996; Blaine and Ribera, 1998). It is possible that Kv2 subunits in situ contribute to channels that activate more rapidly than do homomeric channels expressed heterologously. Whereas the molecular mechanism is not yet known, Kv2 subunits in situ might form heteromeric complexes with members of the Kv5-Kv9 subfamilies; the latter coassemble with and modify the properties of the resultant channel in heterologous systems (Hugnot et al., 1996; Post et al., 1996; Salinas et al., 1997a,b). In addition, Kv2 channel function has been shown to be modified by RNA editing and channel subunit phosphorylation (Murakoshi et al., 1997; Patton et al., 1997).

We also observed a small but significant shift in the $V_{1 / 2}$ of steady-state activation. It is possible that a negative shift could be produced by voltage errors arising from the series resistance. However, our test of this possibility indicated otherwise. An alternative explanation for the negative shift in $V_{1 / 2}$ is that neuronal Kv2 currents have uniquely positive voltage dependencies, consistent with the relatively depolarized activation properties $\left(V_{1 / 2}=25-35 \mathrm{mV}\right)$ of heterologously expressed Kv2 channels 
Table 2. Suppression of Kv2, but not Kv1, channels prolongs the duration of the impulse

\begin{tabular}{lccc} 
Property & Control $(n=24)$ & + Kv1 Mutant $(n=12)$ & + Kv2 Mutant $(n=32)$ \\
\hline Amplitude $(\mathrm{mV})$ & $122 \pm 3$ & $122 \pm 7$ & $121 \pm 2$ \\
Overshoot $(\mathrm{mV})$ & $43 \pm 3$ & $46 \pm 7$ & $42 \pm 2$ \\
Rate of rise $(\mathrm{V} / \mathrm{sec})$ & $174 \pm 11$ & $131 \pm 15^{*}$ & $148 \pm 7^{\mathrm{NS} 2}$ \\
Rising duration $(\mathrm{msec})$ & $1.4 \pm 0.1$ & $1.2 \pm 0.3$ & $1.6 \pm 0.1$ \\
Falling duration $(\mathrm{msec})$ & $1.0 \pm 0.1$ & $1.5 \pm 0.3^{\mathrm{NS}}$ & $3.9 \pm 1.2^{* *}$ \\
Holding potential $(\mathrm{mV})$ & $-79 \pm 1$ & $-76 \pm 3$ & $-79 \pm 1$ \\
Resting potential $(\mathrm{mV})$ & $-47 \pm 2$ & $-38 \pm 3^{\mathrm{NS}}$ & $-42 \pm 1^{\mathrm{NS} 2}$ \\
\hline
\end{tabular}

NS, Not significantly different from control.

NS2, Not significantly different from control or + Kv1 Mutant.

${ }^{*} p<0.02$ versus control.

$* * p<0.005$ versus control.

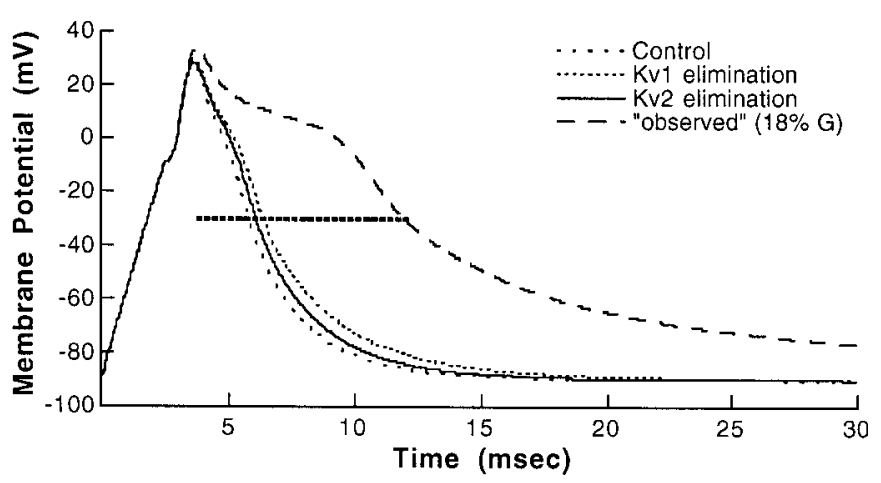

Figure 6. Mathematical simulation of action potentials incorporating observed effects of elimination of Kv1 versus Kv2 channel function elimination. The mathematical model derived by Lockery and Spitzer (1992) was run under control (thick dotted line) and variant $I_{\mathrm{Kv}}$ conditions for mature neurons. $G_{\max }$ was reduced by $33 \%$ alone (Kv1 elimination, thin dotted line) or in combination with a $-5 \mathrm{mV}$ shift in $V_{1 / 2}$ (Kv2 elimination, solid line). The horizontal dashed line indicates the value of halfrepolarization, the voltage at which the impulse duration is determined; its leftmost position is at the time to peak. A simulated action potential produced by reducing $G_{\max }$ by $82 \%$ ("observed", thick dashed line) had a fourfold increase in its duration. The duration of the impulse is defined here as the time between the peak and half-repolarization and was 1.12, 1.25 , and 4 -fold that of control for Kv2 elimination, Kv1 elimination, and "observed", respectively.

(Burger and Ribera, 1996; Blaine and Ribera, 1998). If the voltage dependencies of activation of Kv2 neuronal and oocyte currents are similar, suppression of endogenous neuronal Kv2 currents by the dominant-negative mutant should result in a leftward shift in the $V_{1 / 2}$ of residual $I_{\mathrm{Kv}}$, as we observed. These data suggest that the voltage dependence of the steady-state activation properties (i.e., $V_{1 / 2}$ ) of Kv2 currents in their native location versus a heterologous system are similar, whereas the kinetics of activation differ in these two environments (Fig. 3).

Gene expression profiling of mammalian CNS neurons suggested that native Kv2 currents vary greatly in their voltage sensitivities, with inferred $V_{1 / 2}$ values ranging between -18 and 3 mV (Martina et al., 1998; Baranauskas et al., 1999). Direct examination of Kv2.1 currents in hippocampal neurons using blocking antibodies revealed a higher threshold current with a more positive value for $V_{1 / 2}$ (15 mV; Murakoshi and Trimmer, 1999), similar to what is observed after heterologous expression of recombinant $\mathrm{Kv} 2$ channels. In contrast, antisense elimination of Kv2.1 channels in hippocampal neurons suggested that endogenous Kv2 currents were low-threshold and had a more negative
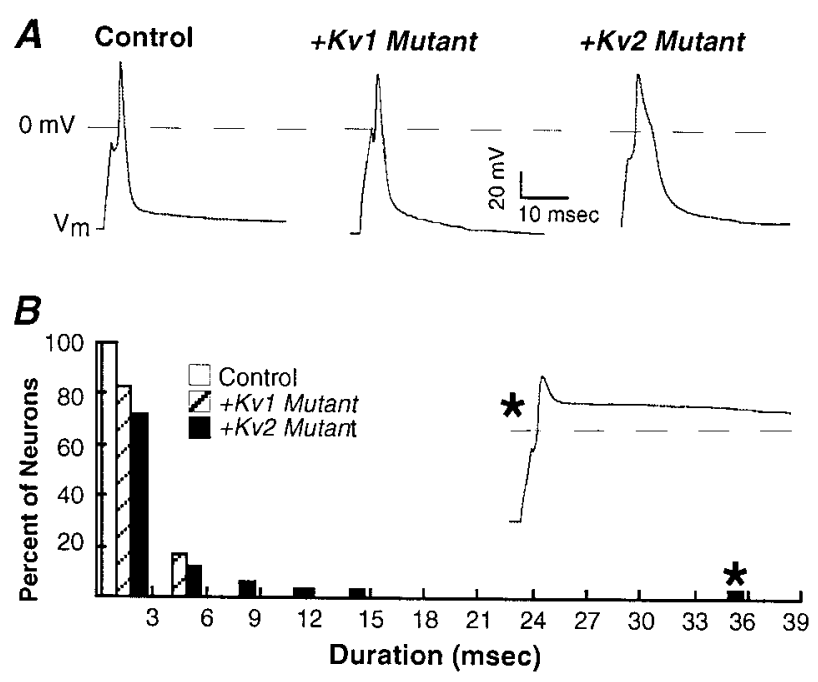

Figure 7. Elimination of $\mathrm{Kv} 2$, but not $\mathrm{Kv} 1$, channels led to significant prolongation of the duration of the action potential. $A$, Action potentials were recorded from mature neurons using the current-clamp mode of the patch-clamp amplifier. A steady level of current was injected to hold the neuronal membrane at approximately $-80 \mathrm{mV}$. Impulses were elicited by a $2.5 \mathrm{msec}$ depolarizing current pulse. Examples representing the "average" impulse recorded from control (left), $+K v 1$ Mutant (middle), and $+K v 2$ Mutant (right) neurons are presented. B, Histogram presenting the distributions of durations of the action potential recorded from control, $+K v 1$ Mutant, and $+K v 2$ Mutant neurons. All mature control neurons had impulse durations of $<3 \mathrm{msec}$. Elimination of Kv2 channels shifted the distribution to much larger values than did suppression of Kv1 channels. The duration of the impulse is defined as the time between peak and half-repolarization. Inset, In one $+K v 2$ Mutant neuron, the action potential had an unusually long duration, and repolarization was not observed during the recording sweep. One neuron $\left.{ }^{*}\right)$ fired an action potential with an unusually long duration, as shown in the inset $(*)$.

$V_{1 / 2}$ (Du et al., 2000). The disparate values for $V_{1 / 2}$ may reflect cell- and activity-dependent modifications of Kv2 channels that occur in situ. Consistent with this possibility, target cells modify the voltage sensitivity of the native $I_{\mathrm{Kv}}$ in Xenopus motoneurons (Nick and Ribera, 2000). In the present study, we restricted analysis to neurons that did not contact other cells to exclude effects of contact-dependent activity on $I_{\mathrm{Kv}}$ activation properties.

In Xenopus, cloned genes that might encode the non-Kv2 residual $I_{\mathrm{Kv}}$ include several Kv1 isotypes, Kv3.1, and Kv4.3 (Ribera, 1990; Ribera and Nguyen, 1993; Lautermilch and Spitzer, 1997; Gurantz et al., 2000). Their contribution to $I_{\mathrm{Kv}}$, although not essential for membrane repolarization, might determine firing frequencies and subthreshold behavior. The Kv1.1 gene has a 
dorsal expression pattern, whereas that of the Kv1.3 gene is more widespread (Ribera and Nguyen, 1993) (A. D. Hofmann and A. B. Ribera, unpublished observations). Kv3.1 mRNA localizes to interneurons initially and to other spinal neurons at mature stages (Gurantz et al., 2000). Antisense elimination of Kv3.1 gene products results in partial suppression of $I_{\mathrm{Kv}}$ and almost a doubling of the duration of the action potential in $\sim 40 \%$ of spinal neurons (Vincent et al., 2000).

Mathematical modeling of the effects of elimination of Kv1 or $\mathrm{Kv} 3.1$ or channels on $I_{\mathrm{Kv}}$ predicted well the observed consequences on the action potential (Vincent et al., 2000; this study). However, the model underestimated the effects of Kv2 channel elimination. The model was based on whole-cell currents and did not consider the effects of channel distribution. Immunocytochemical data indicate that Kv2.2 channels form clusters, whereas Kv2.2 channels are more diffusely localized in mammalian neurons (Hwang et al., 1992; Maletic-Savetic et al., 1995; Rhodes et al., 1995). In addition, neurons expressing Kv2 channels may possess a unique repertoire of ion channels not well represented by the computer model. This hypothesized ensemble of ion channels may provide the appropriate environment for Kv2 channels to function in situ as the primary determinants of action potential repolarization. Consistent with this possibility, Kv2.2 mRNA localizes to the ventral but not dorsal spinal cord; in contrast, the gene coding for calcium-activated potassium current (xSlo) is expressed by dorsal but not ventral spinal neurons (Chouinard et al., 1994; Burger and Ribera, 1996).

Key output neurons of the nervous systems of flies, squid, amphibia, and mammals express Kv2 channels (Butler et al., 1989; Frech et al., 1989; Pak et al., 1991; Hwang et al., 1992; Quattrocki et al., 1994; Burger and Ribera, 1996; Patton et al., 1997; Coetzee et al., 1999). In the mammalian CNS, virtually every neuron expresses Kv2 mRNA (Murakoshi and Trimmer, 1999). Thus, firing properties of several different types of neurons depend on Kv2 channel function in situ. Physiological studies have demonstrated that specific functional components of a current are dynamically modified in response to changes in input or development (Barish, 1986; O’Dowd et al., 1988; Turrigiano et al., 1994; Desai et al., 1999; Golowosch et al., 1999; Spitzer, 1999; Nick and Ribera, 2000). Matching functional current components in situ to their structural counterparts provides essential information for identification of molecular mechanisms underlying development and plasticity of neuronal signaling.

\section{REFERENCES}

Adams DJ, Smith SJ, Thompson SH (1980) Ionic currents in molluscan soma. Annu Rev Neurosci 3:141-167.

Baranauskas G, Tkatch T, Surmeier DJ (1999) Delayed rectifier currents in rat globus pallidus neurons are attributable to Kv2.1 and Kv3.1/3.2 $\mathrm{K}^{+}$channels. J Neurosci 19:6394-6404.

Barish ME (1986) Differentiation of voltage-gated potassium current and modulation of excitability in cultured amphibian spinal neurons. J Physiol (Lond) 375:229-250.

Blaine JT, Ribera AB (1998) Heteromultimeric potassium channels formed by members of the Kv2 subfamily. J Neurosci 18:9585-9593.

Blair LAC (1983) The timing of protein synthesis required for the development of the sodium action potential in embryonic spinal neurons. J Neurosci 3:1430-1436.

Burger C, Ribera AB (1996) Xenopus spinal neurons express Kv2 potassium channel transcripts during embryonic development. J Neurosci 16:1412-1421.

Butler A, Wei A, Baker K, Salkoff L (1989) A family of putative potassium channel genes in Drosophila. Science 243:943-947.

Chouinard HA, Caldwell JH, Ribera AB (1994) Expression of slo transcripts in the embryonic Xenopus laevis nervous system. Soc Neurosci Abstr 20:77.
Coetzee WA, Amarillo Y, Chiu J, Chow A, Lau D, McCormack T, Moreno H, Nadal MS, Ozaita A, Pountney D, Saganich M, Vega-Saenz de Miera E, Rudy B (1999) Molecular diversity of $\mathrm{K}^{+}$channels. Ann NY Acad Sci 868:233-285.

Connor JA, Stevens CF (1971) Voltage clamp studies of a transient outward current in gastropod neural somata. J Physiol (Lond) 213:21-30

Desai NJ, Rutherford LC, Turrigiano GG (1999) Plasticity in the intrinsic excitability of cortical pyramidal neurons. Nat Neurosci 2:515-520.

Du J, Haak LL, Phillips-Tansey E, Russell JT, McBain CJ (2000) Frequency-dependent regulation of rat hippocampal somato-dendritic excitability by the $\mathrm{K}^{+}$channel subunit Kv2.1. J Physiol (Lond) 522 $1: 19-31$.

Frech GC, VanDongen AMJ, Schuster G, Brown A, Joho RH (1989) A novel potassium channel with delayed rectifier properties isolated from rat brain by expression cloning. Nature 340:642-645.

Golowasch J, Abbott LF, Marder E (1999) Activity-dependent regulation of potassium currents in an identified neuron of the stomatogastric ganglion of the crab Cancer borealis. J Neurosci 19:RC33.

Gurantz D, Ribera AB, Spitzer NC (1996) Temporal regulation of Shaker- and Shab-like potassium channel gene expression in single embryonic spinal neurons during $\mathrm{K}+$ current development. J Neurosci 16:3287-3295.

Gurantz D, Lautermilch NJ, Watt SD, Spitzer NC (2000) Sustained upregulation in embryonic spinal neurons of a Kv3.1 potassium channel gene encoding a delayed-rectifier current. J Neurobiol 42:347-356.

Hamill OP, Marty A, Neher E, Sakmann B, Sigworth FJ (1981) Improved patch-clamp techniques for high resolution current recording from cells and cell-free membrane patches. Pflügers Arch 391:85-100.

Hille B (1992) Ionic channels of excitable membranes. Sunderland, MA: Sinauer.

Hodgkin AL, Huxley AF (1952) Currents carried by sodium and potassium ions through the membrane of the giant axon of Loligo. J Physiol (Lond) 116:449-472.

Hugnot JP, Salinas M, LeSage F, Guillemare E, De Weile J, Heurteaux C, Mattei MG, Lazdunski M (1996) Kv8.1, a new neuronal potassium channel with specific inhibitory properties towards Shab and Shaw channels. EMBO J 15:3322-3331.

Hwang PM, Glatt CE, Bredt DS, Yellen G, Snyder SH (1992) A novel $\mathrm{K}^{+}$channel with unique localizations in mammalian brain: molecular cloning and characterization. Neuron 8:473-481.

Jones SM, Ribera AB (1994) Overexpression of a potassium channel gene perturbs neural differentiation. J Neurosci 14:2789-2799.

Lautermilch NJ, Spitzer NC (1997) The Kv4.3 Shal gene is developmentally upregulated in Xenopus embryos and encodes a potassium current modulated by arachidonic acid. Soc Neurosci Abstr 23:1738.

Levitan IB, Rogawski MA (1996) Potassium channels. Neuropharmacology 35:759.

Lockery SR, Spitzer NC (1992) Reconstruction of action potential development from whole cell currents of differentiating spinal neurons. J Neurosci 12:2268-2287.

Maletic-Savatic M, Lenn NJ, Trimmer JS (1995) Differential spatiotemporal expression of $\mathrm{K}^{+}$channel polypeptides in hippocampal neurons in situ and in vitro. J Neurosci 15:3840-3851.

Martina M, Schultz JH, Ehmke H, Monyer H, Jonas P (1998) Functional and molecular differences between voltage-gated $\mathrm{K}+$ channels of fastspiking interneurons and pyramidal neurons of rat hippocampus. J Neurosci 18:8111-8125.

Murakoshi H, Trimmer JS (1999) Identification of the Kv2.1 K ${ }^{+}$channel as a major component of the delayed rectifier $\mathrm{K}^{+}$current in rat hippocampal neurons. J Neurosci 19:1728-1735.

Murakoshi H, Shi G, Scannevin R, Trimmer JS (1997) Phosphorylation of the Kv2.1 K ${ }^{+}$channel alters voltage-dependent activation. Mol Pharmacol 52:821-828

Nick TA, Ribera AB (2000) Synaptic activity modulates presynaptic excitability. Nat Neurosci 3:142-149.

Nieuwkoop PD, Faber J (1967) Normal table of Xenopus laevis. Amsterdam: Daudin.

O’Dowd DK, Ribera AB, Spitzer NC (1988) Development of voltagedependent calcium, sodium and potassium currents in Xenopus spinal neurons. J Neurosci 8:792-805.

Pak MD, Covarrubias M, Ratcliffe A, Salkoff L (1991) A mouse homolog of the Drosophila Shab $\mathrm{K}^{+}$channel with conserved delayed rectifier properties. J Neurosci 11:869-880.

Patton DE, Silva T, Bezanilla F (1997) RNA editing generates a diverse array of transcripts encoding squid $\mathrm{Kv} 2 \mathrm{~K}^{+}$channels with altered functional properties. Neuron 19:711-722.

Post MA, Kirsch GE, Brown AM (1996) Kv2.1 and electrically silent Kv6.1 potassium channel subunits combine and express a novel current. FEBS Lett 399:177-182.

Quattrocki EA, Marshall J, Kaczmarek LK (1994) A Shab potassium channel contributes to action potential broadening in peptidergic neurons. Neuron 12:73-86.

Rhodes KJ, Keilbaugh SA, Barrezueta NX, Lopez KL, Trimmer JS 
(1995) Association and colocalization of $\mathrm{K}^{+}$channel $\alpha$ - and $\beta$-subunit polypeptides in rat brain. J Neurosci 15:5360-5371.

Ribera AB (1990) A potassium channel gene is expressed at neural induction. Neuron 5:691-701.

Ribera AB (1996) Homogeneous development of electrical excitability via heterogeneous ion channel expression. J Neurosci 16:1123-1130.

Ribera AB, Nguyen D-A (1993) Primary sensory neurons express a Shaker-like potassium channel gene. J Neurosci 13:4988-4996.

Ribera AB, Spitzer NC (1989) A critical period of transcription required for differentiation of the action potential of spinal neurons. Neuron 2:1055-1062.

Rosenthal JJ, Vickery RG, Gilly WF (1996) Molecular identification of $\mathrm{SqKv} 1 \mathrm{~A}$. A candidate for the delayed rectifier $\mathrm{K}$ channel in squid giant axon. J Gen Physiol 108:207-219.

Rudy B (1988) Diversity and ubiquity of $\mathrm{K}^{+}$channels. Neuroscience 25:729-749.

Salinas M, de Weille J, Guillemare E, Lazdunski M, Hugnot JP (1997a) Modes of regulation of Shab $\mathrm{K}^{+}$channel activity by the Kv8.1 subunit. J Biol Chem 272:8774-8780.

Salinas M, Duprat F, Heurteaux C, Hugnot JP, Lazdunski M (1997b) New modulatory $\alpha$ subunits for mammalian Shab $\mathrm{K}^{+}$channels. J Biol Chem 272:24371-24379.
Spitzer NC (1999) New dimensions of neuronal plasticity. Nat Neurosci 2:489-491.

Spitzer NC, Lamborghini JE (1976) The development of the action potential mechanism of amphibian spinal neurons isolated in cell culture. Proc Natl Acad Sci USA 73:1641-1645.

Spitzer NC, Ribera AB (1998) Development of electrical excitability in embryonic neurons: mechanisms and roles. J Neurobiol 37:9585-9593.

Storm JF (1990) Potassium currents in hippocampal pyramidal cells. Prog Brain Res 83:161-187.

Tsunoda S, Salkoff L (1995) The major delayed rectifier in both Drosophila neurons and muscle is encoded by Shab. J Neurosci 15:5209-5221.

Turrigiano G, Abbott LF, Marder E (1994) Activity-dependent changes in the intrinsic properties of cultured neurons. Science 264:974-977.

Vincent A, Lautermilch NJ, Spitzer NC (2000) Antisense suppression of potassium channel expression demonstrates its role in maturation of the action potential. J Neurosci 20:6087-6094.

$\mathrm{Xu} \mathrm{H}$, Dixon JE, Barry DM, Trimmer JS, Merlie JP, McKinnon D, Nerbonne JM (1996) Developmental analysis reveals mismatches in the expression of $\mathrm{K}^{+}$channel $\alpha$-subunits and voltage-gated $\mathrm{K}^{+}$channel currents in rat ventricular myocytes. J Gen Physiol 108:405-419. 